\title{
Bias for the (un)attractive self: on the role of attention in causing body (dis)satisfaction
}

Citation for published version (APA):

Smeets, E., Jansen, A., \& Roefs, A. (2011). Bias for the (un)attractive self: on the role of attention in causing body (dis)satisfaction. Health Psychology, 30(3), 360-367. https://doi.org/10.1037/a0022095

Document status and date:

Published: 01/01/2011

DOI:

10.1037/a0022095

Document Version:

Publisher's PDF, also known as Version of record

Document license:

Taverne

Please check the document version of this publication:

- A submitted manuscript is the version of the article upon submission and before peer-review. There can be important differences between the submitted version and the official published version of record.

People interested in the research are advised to contact the author for the final version of the publication, or visit the DOI to the publisher's website.

- The final author version and the galley proof are versions of the publication after peer review.

- The final published version features the final layout of the paper including the volume, issue and page numbers.

Link to publication

\footnotetext{
General rights rights.

- You may freely distribute the URL identifying the publication in the public portal. please follow below link for the End User Agreement:

www.umlib.nl/taverne-license

Take down policy

If you believe that this document breaches copyright please contact us at:

repository@maastrichtuniversity.nl

providing details and we will investigate your claim.
}

Copyright and moral rights for the publications made accessible in the public portal are retained by the authors and/or other copyright owners and it is a condition of accessing publications that users recognise and abide by the legal requirements associated with these

- Users may download and print one copy of any publication from the public portal for the purpose of private study or research.

- You may not further distribute the material or use it for any profit-making activity or commercial gain

If the publication is distributed under the terms of Article $25 \mathrm{fa}$ of the Dutch Copyright Act, indicated by the "Taverne" license above, 


\title{
Bias for the (un)Attractive Self: On the Role of Attention in Causing Body (dis)Satisfaction
}

\author{
Elke Smeets, Anita Jansen, and Anne Roefs \\ Maastricht University
}

\begin{abstract}
Objective: Body dissatisfaction plays a key role in the maintenance of eating disorders, and selective attention might be crucial for the origin of body dissatisfaction. A. Jansen, C. Nederkoorn, and S. Mulkens (2005) showed that eating disorder patients attend relatively more to their own unattractive body parts, whereas healthy controls attend relatively more to their own attractive body parts. In 2 studies, we investigated whether this bias in selective attention is causal to body dissatisfaction and whether an experimentally induced bias for attractive body parts might lead to increased body satisfaction in women who are highly dissatisfied with their bodies. Design: We used a betweensubjects design in which participants were trained to attend to either their self-defined unattractive body parts or their self-defined attractive body parts by use of an eye tracker. Main Outcome Measures: State body and weight satisfaction. Results: Inducing a temporary attentional bias for self-defined unattractive body parts led to a significant decrease in body satisfaction and teaching body-dissatisfied women to attend to their own attractive body parts led to a significant increase in body satisfaction. Conclusion: Selective attention for unattractive body parts can play a role in the development of body dissatisfaction, and changing the way one looks may be a new way for improving body dissatisfaction in women.
\end{abstract}

Keywords: body dissatisfaction, attentional bias, eating disorders, attentional retraining, eye tracking

Body dissatisfaction has been classified as one of the main diagnostic characteristics of eating disorders (American Psychiatric Association, 1994). Individuals with eating disorders suffer from severe feelings of fatness and unattractiveness, and are characterized by intense body loathing (Cash \& Deagle, 1997). Cognitive models attribute an important role to cognitive biases in explaining the etiology and maintenance of eating disorder psychopathology (Faunce, 2002; Lee \& Shafran, 2004; Williamson, White, York-Crowe, \& Stewart, 2004). More specifically, these models explain eating disorder symptoms (i.e., negative body image) in terms of maladaptive knowledge structures (e.g., schemas) that bias the processing of disorder-relevant information (Williamson et al., 2004). One type of cognitive bias that has been studied extensively is attentional bias. An attentional bias (AB) refers to the tendency to selectively attend to and give priority to

Accepted under the editorial term of Robert M. Kaplan.

Elke Smeets, Anita Jansen, and Anne Roefs, Department of Clinical Psychological Science, Maastricht University, Maastricht, The Netherlands.

We thank Ron Hellenbrand for programming the software of the attentional bias training for this study, and the entire technical team of our faculty for their assistance. Tessa Lindelauf is thanked for her help with testing participants for Study 1. Dieuwer Bons, Karen Hopmann, Annika Krause, Tessa Meulendijks, Andréa Odeurs, Eveline Sijbers, and Elsbeth Sprooten are thanked for their assistance in running participants for Study 2.

Correspondence concerning this article should be addressed to Elke Smeets, Faculty of Psychology and Neuroscience, Clinical Psychological Science, Maastricht University, P.O. Box 616, 6200 MD Maastricht, The Netherlands. E-mail: elke.smeets@maastrichtuniversity.nl disorder-relevant information (e.g., Mathews \& MacLeod, 2005; Williamson et al., 2004). Over the last 2 decades, much support has been found for the existence of an attentional bias in eating disorders (for reviews, see Faunce, 2002; Lee \& Shafran, 2004). More specifically, previous research using the modified Stroop paradigm (e.g., see Dobson \& Dozois, 2004), the visual probe paradigm (Rieger et al., 1998; Shafran et al., 2006), and the visual search paradigm (Smeets, Roefs, van Furth, \& Jansen, 2008) have indicated the existence of attentional biases for body- and foodrelated information in eating-disorder patients.

Research from our laboratory shows that eating-disorder patients do not only show an attentional bias for body- and food-related information (i.e., words), but also for specific body parts (Jansen, Nederkoorn, \& Mulkens, 2005). Jansen and colleagues studied attentional bias in eating disorders in a direct way, by exposing participants to pictures of their own body and a control body while simultaneously registering eye movements. Results indicated that eating-disorder patients show a dysfunctional way of looking at their own bodies and a control body, which might maintain eating-disorders psychopathology. More specifically, results showed that when attending to their own body, eating-disorder patients attended more to their selfdefined unattractive body parts than to their self-defined attractive body parts, whereas healthy controls attended more to their own attractive body parts than to their unattractive body parts. The pattern of results was reversed when participants were exposed to another body: Eating-disorder patients attended relatively more to the other's attractive body parts, whereas healthy controls attended relatively more to the other's unattractive body parts (Jansen et al., 2005). 
These data suggest that a tendency for selectively attending to one's own unattractive body parts may maintain or even cause severe feelings of body dissatisfaction. The results of Jansen et al. (2005) are, however, correlational in nature, which precludes drawing conclusions about the causal status of an attentional bias for unattractive body parts in explaining body dissatisfaction. In the present studies the role of selective attention for (un)attractive body parts in body (dis)satisfaction is tested experimentally to determine whether the bias is also causal to (dis)satisfaction.

\section{Study 1}

In Study 1, a negative or a positive body image bias was temporarily induced, by presenting participants with a picture of their own body and training them to selectively attend to either their three self-defined most unattractive body parts (i.e., negative bias training) or their three self-defined most attractive body parts (i.e., positive bias training). All participants who were assigned to the negative bias training receive an additional positive bias training afterward. This was done not only for ethical reasons, but also to test whether temporarily induced feelings of body dissatisfaction can be repaired by means of positive bias training.

In summary, the following hypotheses were tested: (a) The negative bias training will induce a decrease in body and weight satisfaction, whereas the positive bias training will induce an increase in body and weight satisfaction. (b) The positive counter induction training will repair body and weight satisfaction.

\section{Method}

Participants. A total of 47 female undergraduate students were invited to participate in a study ostensibly testing the relationship between perception and concentration, to disguise the real purpose of the experiment. All participants were randomly assigned to either the positive bias training $(n=24)$ or the negative bias training $(n=23)$. Inclusion criteria were no current or past history of eating disorders as assessed during recruitment, and a moderate score on the Body Shape Questionnaire (BSQ; score between 21 and 41), which measures overall body dissatisfaction. BSQ data were obtained through an undergraduate screening session at the beginning of the academic year. Participants had an average body mass index (BMI) of 20.7 ( $S D=1.9$; 16.73-26.2), were on average $19.5(S D=1.3 ; 18-24)$ years old, and scored on average $29.3(S D=5.49 ; 21-41)$ on the BSQ. All participants received either a gift voucher or course credits for their participation. The present study was approved by the local committee for research ethics.

\section{Materials and assessment.}

Pictures. Participants were told that they would have their picture taken in their own underclothes in the lab, and were asked to wear neutral-colored underwear at the day of testing. Pictures were taken with a Nikon D70 SLR camera. The front side of the participant's body was photographed from neck to toes (i.e., without the head being visible), against a white background. Participants stood in a standard position with their arms hanging loosely beside the body.

Individual stimulus selection. To select the body parts for the individually tailored bias training, we asked participants to fill out a so-called perception and concentration ranking questionnaire. As part of this fake questionnaire-with items on, for example, art- works, colors, and hobbies-participants also received a blackand-white printed picture of their own body on which the experimenter had marked 12 body parts. They were asked to name and rank all marked body parts from most attractive (10) to least attractive (1), and to give a grade $(1=$ very negative to $10=$ very positive) for every body part. In a similar way they were asked to rank and give ratings for the distractor categories (e.g., artworks, colors, and hobbies). Furthermore, participants were asked to indicate how satisfied they were with their body overall $(0=$ not satisfied at all to $10=$ very satisfied). The three most attractive or unattractive ranked body parts were selected as stimuli for the bias training.

Apparatus. Participants' eye movements were recorded binocularly by the EyeLink I eye-tracking system distributed by SensoMotoric Instruments (SMI, Berlin, Germany) and SR Research (Mississauga, Ontario, Canada). The Eyelink I eye tracker is an infrared, head-mounted, video-based tracking system (two cameras). The participant was seated at an approximate distance of $57 \mathrm{~cm}$ in front of a computer monitor (1024*768), with her head resting on a chin rest. A Dell Optiplex GX110 Pentium III computer controlled the stimulus presentation, which was programmed in Presentation.

In the present study, eye movements were only registered as part of the gaze-contingent manipulation that was used (for a description, see Attentional bias induction section). In that respect, the collected eye-movement data were not relevant for the hypotheses examined in this article.

Satisfaction and mood. The Body Shape Questionnaire (BSQ; Cooper, Taylor, Cooper, \& Fairburn, 1987) was used to select participants with a moderate level of body dissatisfaction. The BSQ is a psychometrically sound 16-item self-report measure, assessing shape and weight concerns (Rosen, Jones, Ramirez, \& Waxman, 1996). State body satisfaction, state weight satisfaction, and state mood were assessed using 100-mm Visual Analogue Scales (VAS) asking, "How do you feel at this very moment," and ranging from $0=$ extremely dissatisfied to $100=$ extremely satisfied and $0=$ depressed to $100=$ happy.

Attentional bias induction. To induce a temporary attentional bias for the participant's self-defined attractive or unattractive body parts, we developed an individually tailored attentional bias induction training. According to the condition participants were assigned to, each of the self-defined attractive/unattractive body parts was entered in the training procedure. This was done by selecting one of the eight preprogrammed shapes (i.e., squares, rectangles, and circles) that would fit the concerned body part. The same was done for the three neutral objects (i.e., a golf ball and two different types of light bulbs) that were positioned alongside the body. After all body parts and objects were entered in the training procedure, the attentional bias induction training itself started. During the training, participants were instructed to detect and identify the nature of probes appearing at different locations on a fuzzy background picture of the participant's body and three neutral objects in the periphery. The picture of the participant's body was made fuzzy by putting a white overlay picture on top of the original picture, leaving only $25 \%$ of the latter visible. In half of the trials, participants had to discriminate the shape of the 
probe, and in the other half of the trials they had to discriminate the color of the probe. The task for the participant was varied (color and shape) to reduce boredom. During the training, the eye tracker was connected to the stimulus presentation computer. As soon as the participant's gaze matched the location of the probe (as measured by the eye tracker), the underlying body part or neutral object lightened up while the rest of the body picture remained fuzzy. In this way we were sure that the participant looked in the specific body part we wanted her to look in (manipulation check). The illuminated part remained bright during $4 \mathrm{~s}$ to ensure that the participant could have a good look at it. Also, the participant was instructed to keep looking at the illuminated part until the start of the next trial (i.e., the full $4 \mathrm{~s}$ ). This procedure ensured that the overt attention of the participant was directed at the stimulus and, more important, the specific body part.

Manipulations. In both conditions the probe appeared on $10 \%$ of the trials on one of three neutral objects located outside the body. In the negative bias training, the probe appeared on $90 \%$ of the trials on one of the three most unattractive body parts, whereas in the positive bias training, it appeared on $90 \%$ of the trials on one of the three most attractive body parts. The $90 \%$ was divided into $40 \%$ for the most (un)attractive body part, $30 \%$ for the second most (un)attractive body part, and $20 \%$ for the third most (un)attractive body part. The training lasted $20 \mathrm{~min}$, consisting of four blocks of 40 trials. Participants who were assigned to the negative bias condition were given an additional positive bias training of 10 min (i.e., two blocks of 40 trials), which served as a positive counterinduction training.

Procedure. All participants were tested individually. In the first session, the participant was invited to the lab to have her picture taken wearing neutral underwear. After signing the informed consent, she was asked to change into her own neutral underwear and her picture was taken. Then, the participant was given the perception and concentration ranking questionnaire, to select the body parts for the bias training.

The second session took place approximately 1 week later. Before the participant entered the lab, the experimenter inserted the participant's self-defined attractive and unattractive body parts in the computer program. The participant was given a range of VASs measuring body satisfaction, weight satisfaction, and mood among a series of irrelevant filler items. After this, she was instructed to take her place in front of the computer. The eye tracker was placed on her head, which rested on a chin rest during the entire experiment. She was told that the size of her pupils would be registered throughout the session, as a measure of concentration. Nothing was told about eye movements. The participant was told that she was taking part in a visual discrimination task and that she would be presented with one of the pictures of the perception and concentration ranking questionnaire from the first session. In all cases the "randomly chosen" picture was the picture of the participant's own body. Upon appearing on the screen, the picture turned fuzzy and the attentional bias induction training began. Participants were instructed to detect and discriminate the shape (square/circle) or color (red/green) of the probes appearing on the picture as quickly and accurately as possible. At the end of the 20-min training, body and weight satisfaction and mood were measured again. Participants who were assigned to the negative bias training received an additional positive bias training. After completing this positive counter induction training, the participant was asked to fill out the VAS measuring body and weight satisfaction and mood. All participants were debriefed in writing after the experiment was completed.

\section{Results}

Design and statistical analysis. To measure whether the attentional bias training caused changes in body and weight satisfaction and mood, we analyzed results in three 2 (condition: negative bias training vs. positive bias training) $\times 2$ (time: pretraining vs. posttraining) mixed-model analyses of variance (ANOVAs) with the VAS measures of body and weight satisfaction and mood as the main dependent variables. In addition, to assess whether the positive counter induction was successful at restoring levels of state body and weight satisfaction and mood, we conducted planned contrasts comparing posttraining and postcounter induction training levels of body and weight satisfaction and mood.

Participant characteristics. ANOVAs revealed that the two conditions did not differ significantly in age (positive bias training: $M=19.5, S D=1.3$; negative bias training: $M=19.4, S D=1.4$ ), body mass index $\left(\mathrm{BMI}=\right.$ weight $/$ height $^{2}$; positive bias training: $M=20.6, S D=1.8$; negative bias training: $M=20.9, S D=1.9$ ), and BSQ (positive bias training: $M=28.8, S D=5.6$; negative bias training: $M=29.7, S D=5.4)$, all $F \mathrm{~s}(1,45)<1.0$, all $p \mathrm{~s}>$ .05. Furthermore, the conditions did not differ significantly on pretest measures of state body and weight satisfaction and mood as measured by the VAS, all $F_{\mathrm{s}}(1,45)<1.0$, all $p \mathrm{~s}>.05$.

Hypothesis 1: (a) The negative bias training will induce a decrease in body and weight satisfaction, whereas the positive bias training will induce an increase in body and weight satisfaction. (b) The positive counter induction training will repair body and weight satisfaction.

Consistent with our hypothesis, a significant Time $\times$ Condition interaction was found for body satisfaction, $F(1,45)=14.03, p<$ .01 , and for weight satisfaction, $F(1,45)=6.36, p<.05$, qualifying main effects of time for both body satisfaction, $F(1,45)=$ $8.59, p<.01$, and weight satisfaction, $F(1,45)=9.71, p<.01$. We did not find a significant main effect of condition, $F(1,45)=$ 0.25 , ns. Additional planned contrasts for the negative bias condition revealed that participants in the negative bias condition showed a significant decrease in body satisfaction, $F(1,22)=$ 20.34, $p<.001$, and weight satisfaction, $F(1,22)=14.39, p<$ .01 , at postmeasurement in comparison with those at premeasurement (see Table 1). Additional planned contrasts for the positive bias condition revealed that participants in the positive bias condition did not show a significant increase in body satisfaction, $F(1$, $23)=0.36, n s$, nor in weight satisfaction, $F(1,23)=0.19, n s$, at postmeasurement in comparison with those at premeasurement.

The positive counterinduction training, which was given to the participants of the negative bias condition only, did, however, lead to a significant increase in state body satisfaction, $F(1,22)=$ $13.95, p<.01$, and weight satisfaction, $F(1,22)=4.51, p<.05$, from posttraining to postcounterinduction training. Additional paired-samples $t$ tests comparing pretraining and posttraining levels of body and weight satisfaction showed that the positive counterinduction training was effective at restoring levels of state 
Table 1

Means and Standard Deviations of Study 1

\begin{tabular}{|c|c|c|c|c|c|}
\hline \multirow[b]{3}{*}{ Measure } & \multicolumn{3}{|c|}{ Negative bias training } & \multicolumn{2}{|c|}{ Positive bias training } \\
\hline & Pretest & Posttest & Counter induction & Pretest & Posttest \\
\hline & $M(S D)$ & $M(S D)$ & $M(S D)$ & $M(S D)$ & $M(S D)$ \\
\hline Body satisfaction & $5.91(2.15)$ & $4.95(2.11)$ & $5.58(2.08)$ & $5.64(1.64)$ & $5.76(1.65)$ \\
\hline Weight satisfaction & $5.88(1.93)$ & $5.25(1.92)$ & $5.80(1.89)$ & $5.80(2.02)$ & $5.73(1.82)$ \\
\hline Mood & $6.78(1.44)$ & $5.91(1.78)$ & $6.09(2.11)$ & $6.81(1.43)$ & $6.46(1.34)$ \\
\hline
\end{tabular}

body satisfaction, $F(1,22)=2.08, n s$, and weight satisfaction, $F(1$, $22)=0.07, n s$, to premeasurement levels. See Table 1 for means and standard deviations on state body and weight satisfaction.

Mood. A marginally significant Time $\times$ Condition interaction was found, $F(1,45)=3.31, p=.08$, which qualified a main effect of time, $F(1,45)=18.05, p<.01$. We found no significant main effect of condition, $F(1,45)=0.49, n s$. Planned contrasts showed a significant decrease in mood at posttraining in comparison with that at pretraining in the negative training condition, $F(1$, $22)=16.15, p<.01$, and a marginally significant decrease in the positive training condition, $F(1,23)=3,61, p=.07$. Furthermore, additional planned contrasts showed no significant increase in mood after the positive counter induction in comparison with that at posttraining, $F(1,22)=1.05, p=.317$.

See Table 1 for means and standard deviations on state mood. In summary, results show that all participants showed a decrease in mood after the training, but that this decrease was less pronounced for participants in the positive training condition.

Mediation analysis: Does the effect of condition on body/ weight satisfaction occur as a function of mood? In order to make sure that the effect of condition on body/weight satisfaction did not only occur as a function of mood, we performed a meditation analysis. According to Baron and Kenny's (1986) steps of meditation analysis, three consecutive linear regressions were done. As a first step, the predictive value of condition on body/weight satisfaction was examined in a linear regression analysis.

The resulting model reached significance for the analysis of body satisfaction, $F(1,45)=14.04, p<.01, R^{2}=0.24, R^{2}$ adjusted $=0.22$, with $\beta=.48, t=3.75, p<.01$, and the analysis of weight satisfaction, $F(1,45)=6.36, p<.05, R^{2}=0.12, R^{2}$ adjusted $=0.11$, with $\beta=.35, t=2.52, p<.05$. As a second step, the predictive value of condition on mood (mediator) was examined in a separate linear regression analysis. The resulting model was only marginally significant, $F(1,45)=3.31, p=.08, R^{2}=$ $0.07, R^{2}$ adjusted $=0.05$, with $\beta=.26, t=1.82, p=.07$. Finally, as a third step, the predictive value of condition and mood (i.e., mediator) for body/weight satisfaction was examined by entering both measures in another linear regression analysis. The resulting model reached significance for the analysis of body satisfaction, $F(2,44)=8.52, p<.01, R^{2}=0.28, R^{2}$ adjusted $=0.25$, and the analysis of weight satisfaction, $F(2,44)=3.22, p<.05, R^{2}=$ $0.13, R^{2}$ adjusted $=0.08$. Condition (body satisfaction: $\beta=.43$, $t=3.26, p<.01$; weight satisfaction: $\beta=.34, t=2.30, p<.05$ ) reached significance, whereas mood did not (body satisfaction: $\beta=.21, t=1.59, n s$; weight satisfaction: $\beta=.06, t=0.44, n s)$.
In a similar vein, an additional Sobel test confirmed that mood did not mediate the effect of condition on body/weight satisfaction $(z=1.46, p=.014)$.

Taken together, these results show that the effect of condition on body/weight satisfaction was independent of the effect of mood.

\section{Discussion}

The aim of the present study was to experimentally test the causal role of selective attention for (un)attractive body parts in the induction of body (dis)satisfaction. More specifically, we investigated whether training healthy participants to selectively attend to their three most unattractive body parts would lead to increased feelings of body/weight dissatisfaction, and whether training participants to selectively attend to their three most attractive body parts would lead to increased feelings of body/ weight satisfaction. With respect to the negative bias induction training, the present results support the hypothesis that training participants to selectively attend to their own self-defined unattractive body parts induces decreased feelings of body/weight satisfaction. Contrary to our expectations, training participants to selectively attend to their own self-defined attractive body parts did not result in increased feelings of body/weight satisfaction. Interestingly, though, the positive counterinduction training did increase body satisfaction in participants who were first assigned to the negative bias induction training. With respect to the analysis of mood, results show that all participants showed a decrease in mood after the bias training. Interestingly, however, this decrease was smaller for participants in the positive bias condition than for participants in the negative bias condition. These results show that inspecting a picture of one's own body for 20 min negatively affects one's mood; however, when being trained to attend to one's attractive body parts, this effect is less severe than that after attention training in unattractive body parts. Nevertheless, when entered in a meditational model, our results clearly showed that the effect of mood did not account for the effect of the training on participants' level of body and weight satisfaction. Taken together, the present findings provide support for the etiological significance of biased attentional processes in body dissatisfaction.

With respect to the positive bias induction training, the hypothesis that temporarily inducing selective attention for self-defined attractive body parts would lead to increased feelings of body satisfaction was only partly supported. The positive bias training in healthy women did not induce more satis- 
faction, although we had selected a group that had some room for improvement because of their scores in the middle range of the BSQ. It might not only be more difficult to induce a positive body image bias in reasonably satisfied women, it might in general be more difficult to induce positive biases than negative biases.

We could, however, find some support for the idea that a positive bias training leads to increased body satisfaction: The positive training did work for the group that first received a negative body image bias induction and, as a consequence of that training, showed a recent significant decrease in body satisfaction. These women had of course more room for improvement than the women who were assigned to the positive bias training without preceding negative bias induction, but a more crucial difference might be that their relative dissatisfaction was recently induced and thus not that tenacious.

The finding that a temporary decrease in body and weight satisfaction could be reversed by training participants to selectively attend to their three most attractive body parts (i.e., positive counterinduction training) shows that changes in a positive direction are possible. Therefore, it would be of great interest to investigate whether the positive bias training would also be beneficial to women with high levels of body dissatisfaction.

\section{Study 2}

To investigate whether the positive bias training will be effective in a sample of women with higher levels of trait body dissatisfaction, a second study was conducted in which the effects of a positive bias training were compared with the effects of random exposure to the body (i.e., control training). Our control training was developed as an experimental analogue of body exposure therapy, which is a commonly used technique in clinical settings nowadays (Hilbert, Tuschen-Caffier, \& Vogele, 2002; Key et al., 2002; Rushford \& Ostermeyer, 1997; Tuschen-Caffier, Vögele, Bracht, \& Hilbert, 2003). Despite its common use, little is known about the exact effects of this therapy.

Participants were presented with a picture of their own body, and they were trained to either attend to their three most attractive body parts (i.e., positive bias training) or to attend to all of their body parts (i.e., control training). The following hypothesis was tested: The positive bias training will induce an increase in body and weight satisfaction, whereas the control training will not lead to changes in body and weight satisfaction.

\section{Methods}

Participants. A total of 21 female undergraduate students who were selected on the basis of a high score on the BSQ were invited to participate in a study ostensibly testing the relation between perception and concentration. All participants were randomly assigned to either the positive bias training $(n=11)$ or the control training $(n=10)$. Inclusion criteria were no current or past history of eating disorders as assessed during recruitment, and a high score on the BSQ (score $\geq 39$ ), which measures overall body dissatisfaction. BSQ data were obtained through an undergraduate screening session 3 weeks before the start of the experiment. Participants had an average BMI of 23.19 (SD = 3.36; 18.51$32.69)$, were on average $20.7(S D=1.6 ; 18-24)$ years old, and scored on average $51.1(S D=11.55 ; 39-81)$ on the BSQ. All participants received course credits for their participation. The present study was approved by the local committee for research ethics.

\section{Materials and assessment.}

Pictures. The same procedure as in Study 1 was used.

Individual stimulus selection. To select the body parts for the individually tailored bias training, we asked participants to fill out the same perception and concentration ranking questionnaire as in Study 1.

Apparatus. During the attentional bias induction, participant's eye movements were registered minocularly by the EyeLink 1000 remote camera system distributed by SR Research. The EyeLink 1000 eye tracker is an infrared, remote, video-based tracking system (two cameras). The participant was seated at an approximate distance of $57 \mathrm{~cm}$ in front of a computer monitor $(1024 * 768)$, with her head resting on a chin rest.

Satisfaction and mood. See Study 1 for a description.

Attentional bias induction. The procedure of the positive attentional bias induction was similar to that of Study 1, with the exception that the present training was 15 min longer than the previous one (because of four extra trials per block). In the present study, the effects of the positive bias training were compared with the effects of control training.

Manipulations. In both conditions the probe appeared in $10 \%$ of the trials on one of three neutral objects located outside the body. In the positive bias training, the probe appeared on $90 \%$ of the trials on one of the three most attractive body parts, whereas in the control training, it appeared on $90 \%$ of the trials randomly on all body parts, except for the participant's most attractive and most unattractive body parts. For the positive bias training, the $90 \%$ was divided into $40 \%$ for the most attractive body part, $30 \%$ for the second most attractive body part, and $20 \%$ for the third most attractive body part. For the control training, the $90 \%$ was evenly divided over 10 body parts. The training lasted $35 \mathrm{~min}$, consisting of four blocks of 44 trials.

Procedure. The procedure was exactly the same as that of Study 1.

\section{Results}

Design and statistical analysis. To measure whether the attentional bias training caused changes in body and weight satisfaction and mood, we analyzed results in three 2 (condition: positive bias training vs. control training) $\times 2$ (time: pretraining vs. posttraining) mixed- model ANOVAs with the VAS measures of body and weight satisfaction and mood as the main dependent variables.

Participant characteristics. ANOVAs revealed that the two conditions did not differ significantly in age (positive bias training: $M=20.36, S D=1.4$; control training: $M=21, S D=1.9)$, BMI (=weight/height ${ }^{2}$; positive bias training: $M=23.28, S D=2.8$; control training: $M=23.10, S D=3.9$ ), and BSQ (positive bias training: $M=52.20, S D=13.6$; control training: $M=50.10$, $S D=9.02)$, all $F \mathrm{~s}(1,19)<1.0, n s$. Furthermore, the conditions did not differ significantly on pretest measures of state body, $F(1$, $19)=1.63, n s$, and weight satisfaction and mood as measured by the VAS, both $F_{\mathrm{s}}(1,19)<1.0$, both $p \mathrm{~s}>.05$. 
Hypothesis: The positive bias training will induce an increase in body and weight satisfaction, whereas the control training will not lead to any changes in body and weight satisfaction.

In accordance with our hypothesis, a significant Time $\times$ Condition interaction was found for body satisfaction, $F(1,19)=$ $20.42, p<.001$, and for weight satisfaction, $F(1,19)=11.09, p=$ .004 , qualifying main effects of time for weight satisfaction, $F(1$, $19)=14.08, p=.001$, but not for body satisfaction, $F(1,19)=$ $0.52, n s$. We did not find a significant main effect of condition, however, $F(1,19)=0.20, n s$.

Additional planned contrasts for the positive bias training revealed that participants in the positive bias condition showed a significant increase in body satisfaction, $F(1,10)=80.32, p<$ .001 , and in weight satisfaction, $F(1,10)=48.96, p<.001$, at postmeasurement in comparison with those at premeasurement. Additional planned contrasts for the control training revealed that participants in the control condition showed a marginally significant decrease in body satisfaction, $F(1,9)=3.59, p=.09$, but no changes in weight satisfaction, $F(1,9)=0.06, n s$, at postmeasurement in comparison with that at premeasurement. See Table 2 for means and standard deviations on state body and weight satisfaction.

Mood. With regard to the mood analyses, we found no significant Time $\times$ Condition interaction, $F(1,19)=.24, n s$, and no main effect of condition, $F(1,19)=0.19$, $n s$. We did find a significant main effect of time, $F(1,19)=7.89, p<.05$. See Table 2 for means and standard deviations on mood. In conclusion, it was shown that all participants showed a decrease in mood after the training, regardless of which condition they were assigned to.

\section{Discussion}

The aim of the present study was to investigate whether a positive bias training, in comparison with control training, would increase body and weight satisfaction in women who were highly dissatisfied with their bodies. In accordance with our hypothesis, it was shown that training highly dissatisfied women to selectively attend to their three most attractive body parts led to increased feelings of body and weight satisfaction. In contrast, being trained to attend to all body parts (control training) did not lead to any positive or negative changes in body and weight satisfaction. With respect to the analysis of mood, results demonstrated that all participants showed a decrease in mood after the training. This effect could be explained by the repetitive and possibly boring nature of the training.
The present results clearly show that focusing on one's own attractive body parts during a 35-min training session might be a promising intervention for improving women's body image.

\section{General Discussion}

The present studies show that the way women attend to their bodies can cause them to feel either worse or better about their bodies. More specifically, it was shown that training healthy participants to focus on their most unattractive body parts caused them to feel less satisfied with their body, whereas training those highly dissatisfied participants to focus on their most attractive body parts caused them to feel more satisfied with their bodies. This latter effect also occurred in healthy participants who received the positive bias training right after they had finished a negative bias training that had made them temporarily more dissatisfied with their bodies. It should be noted that the attention of our participants had been successfully manipulated during the training of both studies, because of the gaze-dependent illumination of the trained body parts.

In general, these findings provide support for the causal role of selective attention in body (dis)satisfaction. Elaborating on the findings of Jansen et al. (2005), it was shown that training healthy participants to view their bodies in a dysfunctional or biased way results in increased feelings of body dissatisfaction. More precisely, only a brief 20-min negative bias training made healthy participants feel worse about their bodies. As eating-disorder patients have been shown to selectively attend to their own unattractive body parts (Jansen et al., 2005), it might be suggested that repeatedly attending to these parts might not only cause but also maintain intense feelings of body dissatisfaction. In this line, it would be worthwhile to investigate in future research whether reducing the attentional bias for unattractive body parts in eating-disorder patients might lead to a reduction in body dissatisfaction.

In addition, the present findings are in line with recent research by Smith and Rieger (2006) and by Engel and colleagues (2006), supporting the causality of selective attention for body-related words in body dissatisfaction and eating concerns. Smith and Rieger (2006) used an attentional probe task to train healthy participant's attention toward or away from negative shape/weight-related words, neutral words, or negatively valenced emotion words. After the training, participants were presented with a body image challenge (i.e., exposure to advertisements of slender models) to assess their levels of body dissatisfaction. As was expected, results indicated that training

Table 2

Means and Standard Deviations of Study 2

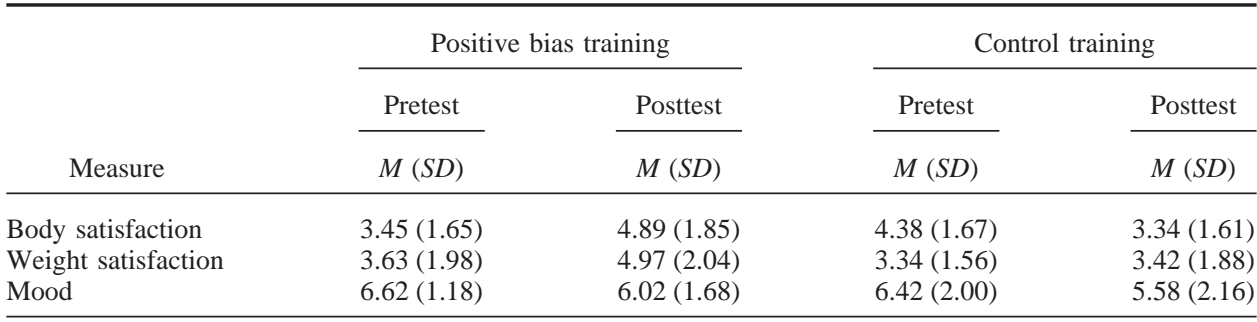


an attentional bias toward shape/weight-related words, in comparison with both control groups, led to increased levels of body dissatisfaction in healthy participants.

Engel and colleagues (2006) also used an attentional probe task and trained healthy participant's attention toward or away from body/shape-related words, after which their concerns about eating and body were assessed. In contrast to the findings of Smith and Rieger (2006), Engel and colleagues (2006) found that training attention away from body/shape-related words resulted in greater concerns about body and eating than did training attention toward body/shape-related words. Although it is unclear why these studies show opposite results, both studies confirm a causal relation between disturbed attentional processes and the development of eating-disorder symptoms, which nicely dovetails with the findings of the present study.

The results of Study 2 show that changing the way women dissatisfied with their bodies attend to their bodies leads to positive changes in the way they feel about their bodies.

More precisely, training dissatisfied women to attend to their three most attractive body parts for 35 min proved preliminarily to be a new technique for improving feelings of body dissatisfaction. Exposing the same group of participants to all of their body parts for $35 \mathrm{~min}$, however, did not lead to increased feelings of body satisfaction. In other words, exposing dissatisfied women to a picture of their own bodies without training them to attend to their bodies in a specific way (i.e., attend to attractive body parts) did not lead to any changes in the way these women felt about their bodies. It must be noted, however, that the absence of this effect might be due to our relatively small sample size. Future research replicating the same study with a larger sample size is necessary to unravel the exact effects of the control training. Furthermore, it would be of interest to establish in future research whether the effect of the positive bias training would still be present after a longer time, and whether it would get stronger after more frequent training sessions.

Our findings might have some preliminary implications for the widespread use of body exposure therapy in the treatment of eating-disorder patients. In light of the current findings, one might reason that caution might be warranted when exposing eating- disorder patients to their own bodies in a mirror, because they have been shown to have the natural tendency to attend to their unattractive body parts (Jansen et al., 2005). Future studies are, however, necessary to corroborate this line of reasoning.

Finally, even though our findings are still preliminary and in need of replication, there is some reason to believe that treatment programs might benefit from incorporating procedures to teach eating-disordered and other patients dissatisfied with their bodies-for example, body dysmorphic patients (Mulkens \& Jansen, 2009) - to focus more on their beautiful body parts. Future research should find out under which conditions a positive bias training might lead to a more positive body image, and whether a more intensive and repetitive positive bias training might be of benefit for an increase in body satisfaction in a clinical sample. A main empirical question that remains for future research is whether training eating-disorder patients to selectively attend to their most beautiful body parts leads to an increase in body satisfaction. Essentially, one would want to address this hypothesis in a group of patients who are at the end of their treatment program. Given the likelihood that eatingdisorder patients who are at the beginning of their treatment would rank their most skinny-looking body parts as the most beautiful, training them to focus even more on these parts could increase their reluctance to gain weight, and even reinforce the glorification of their skinny bodies. Therefore, it seems advisable to restrict the investigation of the effect of positive body training to patients who have or approach a healthy body weight. In this perspective, it can be hypothesized that the clinical implications of the positive bias training might be predominantly in relapse prevention rather than in the acute treatment of eating-disorder psychopathology.

In conclusion, the present findings provide support for the etiological significance of biased attentional processes in body dissatisfaction and provide a new and simple way for improving women's body image.

\section{References}

American Psychiatric Association. (1994). Diagnostic and statistical manual of mental disorders (4th ed.). Washington, DC: Author.

Baron, R. M., \& Kenny, D. A. (1986). The moderator-mediator variable distinction in social psychological research: Conceptual, strategic and statistical considerations. Journal of Personality and Social Psychology, 51, 1173-1182.

Cash, T. F., \& Deagle, E. A. (1997). The nature and extent of body image disturbances in anorexia nervosa and bulimia nervosa: A meta-analysis. International Journal of Eating Disorders, 22, 107-125.

Cooper, P. J., Taylor, M. J., Cooper, Z., \& Fairburn, C. G. (1987). The development and validation of the Body Shape Questionnaire. International Journal of Eating Disorders, 6, 485-494.

Dobson, K. S., \& Dozois, D. J. A. (2004). Attentional biases in eating disorders: A meta-analytic review of Stroop performance. Clinical Psychology Review, 23, 1001-1022.

Engel, S. G., Robinson, M. D., Wonderlich, S. J., Meier, B., Wonderlich, S. A., Crosby, R. D., ... Mitchell, J. E. (2006). Does the avoidance of body and shape concerns reinforce eating disordered attitudes? Evidence from a manipulation study. Eating Behaviors, 7, $368-374$.

Faunce, G. J. (2002). Eating disorders and attentional disorders: A review. Eating Disorders, 10, 125-139.

Hilbert, A., Tuschen-Caffier, B., \& Vögele, C. (2002). Effects of prolonged and repeated body image exposure in binge-eating disorder. Journal of Psychosomatic Research, 52, 137-144.

Jansen, A., Nederkoorn, C., \& Mulkens, S. (2005). Selective visual attention for ugly and beautiful body parts in eating disorders. Behaviour Research and Therapy, 43, 183-196.

Key, A., George, C. L., Beattie, D., Stammers, K., Lacey, H., \& Waller, G. (2002). Body image treatment within an inpatient program for anorexia nervosa: The role of mirror exposure in the desensitization process. International Journal of Eating Disorders, 31, 185-190.

Lee, M., \& Shafran, R. (2004). Information processing biases in eating disorders. Clinical Psychology Review, 24, 215-238.

Mathews, A., \& MacLeod, C. (2005). Cognitive vulnerability to emotional disorders. Annual Review of Clinical Psychology, 1, 167-195.

Mulkens, S., \& Jansen, A. (2009). Mirror gazing increases attractiveness in satisfied, but not in dissatisfied women: A model for body dysmorphic disorder? Journal of Behavior Therapy and Experimental Psychiatry, 40, 211-218.

Rieger, E., Schotte, D. E., Touyz, S. W., Beumont, P. J. V., Griffiths, R., \& Russel, J. (1998). Attentional biases in eating disorders: A visual probe detection procedure. International Journal of Eating Disorders, 23, 199-205. 
Rosen, J. C., Jones, A., Ramirez, E., \& Waxman, S. (1996). Body Shape Questionnaire: Studies of validity and reliability. International Journal of Eating Disorders, 20, 315-319.

Rushford, N., \& Ostermeyer, A. (1997). Body image disturbance and their change with videofeedback in anorexia nervosa. Behaviour Research and Therapy, 5, 389-398.

Shafran, R., Lee, M., Cooper, Z., Palmer, R. L., \& Fairburn, C. G. (2007). Attentional bias in eating disorders. International Journal of Eating Disorders, 40, 369-380.

Smeets, E., Roefs, A., van Furth, E., \& Jansen, A. (2008). Attentional bias for body and food in eating disorders: Increased distraction, speeded detection, or both? Behaviour Research and Therapy, 46, 229-238.

Smith, E., \& Rieger, E. (2006). The effect of attentional bias toward shapeand weight-related information on body dissatisfaction. International Journal of Eating Disorders, 39, 509-515.

Tuschen-Caffier, B., Vögele, C., Bracht, S., \& Hilbert, A. (2003). Psychological responses to body shape exposure in patients with bulimia nervosa. Behaviour Research and Therapy, 41, 573-586.

Williamson, D. A., White, M. A., York-Crowe, E., \& Stewart, T. M (2004). Cognitive-behavioral theories of eating disorders. Behavior Modification, 28, 711-738.

\section{Members of Underrepresented Groups: Reviewers for Journal Manuscripts Wanted}

If you are interested in reviewing manuscripts for APA journals, the APA Publications and Communications Board would like to invite your participation. Manuscript reviewers are vital to the publications process. As a reviewer, you would gain valuable experience in publishing. The P\&C Board is particularly interested in encouraging members of underrepresented groups to participate more in this process.

If you are interested in reviewing manuscripts, please write APA Journals at Reviewers@apa.org. Please note the following important points:

- To be selected as a reviewer, you must have published articles in peer-reviewed journals. The experience of publishing provides a reviewer with the basis for preparing a thorough, objective review.

- To be selected, it is critical to be a regular reader of the five to six empirical journals that are most central to the area or journal for which you would like to review. Current knowledge of recently published research provides a reviewer with the knowledge base to evaluate a new submission within the context of existing research.

- To select the appropriate reviewers for each manuscript, the editor needs detailed information. Please include with your letter your vita. In the letter, please identify which APA journal(s) you are interested in, and describe your area of expertise. Be as specific as possible. For example, "social psychology" is not sufficient-you would need to specify "social cognition" or "attitude change" as well.

- Reviewing a manuscript takes time (1-4 hours per manuscript reviewed). If you are selected to review a manuscript, be prepared to invest the necessary time to evaluate the manuscript thoroughly. 